\title{
Campo de atuação do(a) psicólogo(a) no movimento da Economia Solidária no Brasil
}

\author{
Iara Lais Raittz Baratieri ${ }^{1}$ e Marilene Zazula Beatriz ${ }^{2}$ \\ Universidade Tecnológica Federal do Paraná (Curitiba, PR)
}

\begin{abstract}
Esta pesquisa teve como objetivo levantar a atuação do profissional de psicologia no espaço do movimento da Economia Solidária no Brasil. Trata-se de um estudo exploratório com base em um levantamento de dados de fonte primária, que foram submetidos a análise estatística descritiva. A amostra foi composta por 123 sujeitos, sendo 26 homens e 97 mulheres. Levantou-se que grande parte dos(as) psicólogos(as) atua em entidades de apoio junto a coletivos informais, incubadoras tecnológicas, cooperativas populares e associações de trabalho. Os temas mais trabalhados no âmbito comportamental são: relações interpessoais, autogestão, tomada de decisões, conflitos, disseminação dos valores da cooperação e participação; e no âmbito técnico são: gestão básica, inserção do produto no mercado, desenvolvimento local e consciência crítica sobre o trabalho assalariado.
\end{abstract}

Palavras-chave: Trabalho, Economia solidária, Psicologia do trabalho, Psicologia comunitária, Atuação do psicólogo.

The role of psychologists in the solidarity economy movement in Brazil

This study aims to get the professional performance in the movement of Solidarity Economy in Brazil. This is an exploratory study based on data collection of primary source, which were submitted to statistic and descriptive analysis. The sample was composed by 123 subjects ( 26 males and 97 females). It was found that most part of the psychologists works on support agencies, technological incubators, popular cooperatives and working associations. The themes more worked on the behavioral ambit are: interpersonal relationships, self-management, decisionmaking, conflicts and spreading the values of cooperation and participation; and on technical ambit are: basic management, insertion of the product in the market, local development and critical conscience about employment.

Keywords: Work, Solidarity economy, Work psychology, Community psychology, Role of the psychologist.

\section{Introdução}

\begin{abstract}
A presente pesquisa teve como objetivo levantar a atuação do profissional de psicologia no movimento da Economia Solidária no Brasil. A Economia Solidária está aqui entendida como uma forma de fazer economia baseada em valores como: autogestão, cooperação, democracia, solidariedade, respeito à natureza, valorização do ser humano, distribuição de renda e uma forma de organização do trabalho que busque a inclusão e o fomento para a criação e/ou fortalecimento de políticas públicas que se contraponham ao sistema econômico capitalista (Cartilha da Campanha Nacional de Mobilização Social, 2007; Coser \& Cortegoso, 2007; Lima, 2008; Singer, 2002).

O interesse por ligar a atuação do profissional da Psicologia (como área de conhecimento) e a Economia Solidária (como campo de atuação) ocorreu quando se começou a questionar sobre a formação do psicólogo face às exigências específicas dessa forma de organização do trabalho versus o crescimento de empreendimentos econômicos solidários no Brasil. Da mesma forma, constatou-se a baixa publicação de estudos científicos que contemplassem tal atuação. Nesse sentido, optou-se pela realização de uma pesquisa que pudesse mapear a atuação e a formação dos(as) psicólogos(as) atuantes, ou que já atuaram, na Economia Solidária.
\end{abstract}

1 Psicóloga formada pela Universidade Tuiuti do Paraná. Bolsista do Programa de Iniciação Científica em 2010/2011.

2 Professora adjunta na área de Psicologia da Universidade Tecnológica Federal do Paraná. Professora Colaboradora do Mestrado de Psicologia da Universidade Tuiuti do Paraná. 
Com relação à formação dos(as) psicólogos(as), observa-se que dispõem, em sua maioria, de modelos e estratégias clássicas, utilizadas nas áreas tradicionais da psicologia clínica, educacional e organizacional. Entretanto, para se trabalhar com a Economia Solidária, partindo-se das demandas das comunidades e, mais especificamente, dos grupos de trabalhos informais, das cooperativas populares, das associações, das feiras de economia solidária, entre outros formatos dessa organização de trabalho, necessita-se de uma instrumentalização teórica e ideológica diferenciada. A área da Psicologia Organizacional e do Trabalho, por exemplo, utiliza-se de técnicas e de instrumentos direcionados para o trabalhador do modo de produção capitalista. É nisso que apoiam-se Coutinho, Beiras, Picinin e Lükmann (2005, p. 10) quando comentam que "os métodos tradicionais da psicologia do trabalho, construídos nos setores de recursos humanos das organizações de grande porte, não são compatíveis com as organizações solidárias".

Então, qual deveria ser a postura ético-política, bem como a instrumentalização do profissional da psicologia, para se trabalhar com a Economia Solidária? Concorda-se com Veronese e Guareschi (2005) que é preciso um profissional habilitado para auxiliar nas transformações da subjetividade durante o processo de construção da cultura da solidariedade; o processo de constituição dos grupos para os empreendimentos; o processo de mudança da heteronomia para a autonomia; a "micro-política das relações laborais" (p. 66) para o esclarecimento de conceitos como democracia, política e ações; bem como o desenvolvimento de relações intrafamiliar, grupal e comunitária. É necessário, portanto, que haja um processo permanente de autocrítica desse profissional para evitar que a Economia Solidária se subordine à lógica do capital. Segundo Spink (2004), isso requer uma psicologia comprometida com a ação social que se dispõe a assumir os fenômenos da coletividade e a se inserir nos processos do cotidiano. Nesse sentido, é necessária uma psicologia preocupada com a emancipação, uma ciência responsável e atuante no processo de desalienação do indivíduo e dos grupos sociais.

Por isso, esta pesquisa tem como objetivo compreender a atuação do(a) psicólogo(a) no espaço do movimento da Economia Solidária no Brasil, tendo em vista seu desenvolvimento nas duas últimas décadas. Para melhor organização do artigo, optou-se por dividi-lo da seguinte forma: na primeira parte, revisam-se brevemente algumas abordagens teóricas sobre a Economia Solidária, bem como a atuação do profissional de psicologia; na segunda, apresentase a metodologia de pesquisa propriamente dita; e, na terceira, discutem-se os resultados da referida pesquisa, além das considerações finais.

\section{Economia Solidária}

A Economia Solidária propõe uma lógica de funcionamento da economia que deve ser solidária em vez de competitiva (Lima, 2008; Rosenfield, 2003): deve privilegiar o coletivo ao individual. No entanto, uma das grandes dificuldades encontradas pelo movimento da Economia Solidária é que se vive em uma sociedade em que predominam os valores da competitividade e do individualismo, dificultando sobremaneira a introdução da cultura solidária, por significar enfrentar inúmeras contradições e superar algumas delas. $\mathrm{O}$ excesso de competitividade e ambição gerou impactos sociais, ambientais, culturais e econômicos devastadores, a ponto de exigir uma grande e eficiente soma de esforços para sua reversão. Os indivíduos estão tão habituados a agir individualmente que a articulação eficiente de ações coletivas acaba se tornando um grande desafio (Arroyo, 2008).

No entanto, segundo Singer (2002), a solidariedade na economia

só pode se realizar se ela for organizada igualitariamente pelos que se associam para produzir, comercializar, consumir ou poupar. A chave dessa proposta é a associação entre iguais em vez do contrato entre desiguais. Na cooperativa de produção, protótipo de empresa 
Solidária, todos os sócios têm a mesma parcela do capital e, por decorrência, o mesmo direito de voto em todas as decisões (p. 9).

Apesar de o cooperativismo ter surgido no Brasil no início do século XX, trazido pelos emigrantes europeus, é somente com a crise econômica social das décadas de 1980 e 1990, provocada, em parte, pela abertura de mercado para empresas multinacionais, pelo aumento do desemprego estrutural causado pela tecnologia, pela demissão de milhões de trabalhadores e pelo aumento da exclusão social, que o movimento cooperativo, por meio da Economia Solidária, renasceu no Brasil (Singer, 2002).

Para alguns, a Economia Solidária surge como uma forma de combater as consequências advindas do modelo de produção capitalista. É uma maneira que os trabalhadores encontraram de aumentar/obter sua renda, de incluir-se novamente no mundo do trabalho. Os empreendimentos econômico-solidários passam a ser, então, uma oportunidade de resgate da dignidade humana e do desenvolvimento de autoajuda e ajuda mútua.

Para outros, o movimento da Economia Solidária propõe, em seu bojo, a superação do modelo capitalista, deixando de ser apenas uma reação da sociedade frente à falta de emprego, pois isso fatalmente a transformaria em mais uma forma complementar da economia capitalista (Singer, 2002). Já Souza (comunicação pessoal, 28 de março de 2006) acredita que as transformações da sociedade ocorrem simultaneamente ao sistema hegemônico, sendo construídas a partir do sistema vigente até alcançar maturidade suficiente para se transformar definitivamente. Essa transformação deve vir embasada por um processo educativo que leve as pessoas a refletirem sobre os princípios da Economia Solidária, principalmente aquelas populações excluídas do sistema que, aliadas aos movimentos sociais, buscam resgatar a autoestima e reagir contra o assistencialismo.

Nesse sentido, a área de conhecimento da psicologia pode contribuir sobremaneira; por exemplo, a psicologia comunitária, que, historicamente, esteve voltada para os grupos populares. A psicologia comunitária pode, então, aparecer no cenário da Economia Solidária privilegiando o trabalho com grupos, colaborando com a formação e o incremento da consciência crítica, para a construção de uma identidade social e individual (Freitas, 1996, citado por Brito \& Figueiredo, 1997).

Já a psicologia organizacional e do trabalho, inicialmente conhecida como psicologia industrial, surge no fim do século XIX e início do século XX. Conforme Zanelli e Bastos (2004), esta área da psicologia está associada à crescente industrialização que ocorreu nos países ocidentais dominantes e sua tarefa central pode ser resumida em explorar, analisar e compreender como interagem os grupos, as pessoas e as organizações. Tem a finalidade de construir estratégias e procedimentos que possam promover, preservar e restabelecer a qualidade de vida e o bem-estar das pessoas (Zanelli \& Bastos, 2004).

No entanto, sua forma de atuação não leva em consideração a exclusão social e o desemprego, pois atua para atender à lógica do capital, quando implanta nas empresas: processos de recrutamento e seleção excludentes; avaliações de desempenho que visam à melhoria do desempenho empresarial; treinamentos e políticas de desenvolvimento em busca da melhoria da qualidade dos produtos; programas de qualidade de vida que, em última instância, visam a manutenção da empresa e não a do trabalhador; trabalhos em equipe com o objetivo de unir os trabalhadores para o alcance de maior lucratividade. Ou seja, o foco maior é a empresa. Os trabalhadores e a trabalhadoras são peças dessa engrenagem, os quais, enquanto úteis ao processo produtivo, serão tratados como "colaboradores". Caso contrário, poderão ser facilmente descartados.

Nesse sentido, buscar uma psicologia do trabalho vinculada à visão da psicologia social e comunitária se faz importante, por ter sua história voltada para trabalhos com o coletivo e, 
assim, implica a melhoria das relações sociais, tentando uma consciência crítica e o fortalecimento desses sujeitos e da comunidade.

Esta pesquisa levantou os dados para a compreensão da atuação do(a) psicólogo(a) no espaço do movimento da Economia Solidária e, para isso, utilizou-se de um instrumento para mediar essa aproximação, conforme descrito na metodologia a seguir.

\section{Metodologia}

\section{Participantes}

A população desta pesquisa compreendeu os(as) profissionais psicólogos(as) atuantes, ou que já atuaram, com a Economia Solidária no Brasil. A amostra foi composta por 123 sujeitos, sendo 26 do sexo masculino e 97 do sexo feminino, com idades entre 22 e 60 anos.

\section{Instrumento}

Esta pesquisa se constituiu em um estudo exploratório com base em um levantamento de dados de fonte primária (questionário virtual). Os dados secundários subsidiaram a elaboração do questionário "Psicólogos(as) atuantes em Economia Solidária", a partir do levantamento de material bibliográfico; da participação em fóruns regional e estadual; de cartilhas de mapeamento de empreendimentos solidários no Brasil (2005 e 2007); da participação no III Encontro Estadual de Economia Solidária e na I Feira Universitária de Economia Solidária da Universidade Tuiuti do Paraná; e de fôlderes e materiais publicitários sobre Economia Solidária.

O questionário foi dividido em blocos de perguntas abordando: o Perfil do(a) Psicólogo(a) (dados pessoais, região onde se formou em psicologia, tempo de experiência em psicologia, formação em outras áreas) e a Atuação do(a) Psicólogo(a) com a Economia Solidária (tempo de experiência em Economia Solidária; como conheceu a Economia Solidária; participação em fóruns regionais e estaduais; relato das atividades, facilidades e dificuldades encontradas; tipo e natureza do empreendimento; temas trabalhados; linha teórica adotada; motivação para trabalhar com Economia Solidária; disciplinas oferecidas na graduação; e questões relacionadas à natureza do empreendimento em que o(a) psicólogo(a) atua, ou já atuou). O questionário foi elaborado para ser respondido tanto pelo profissional que estava atuando quanto pelo que já atuou com Economia Solidária. A construção do questionário passou por dezesseis alterações até sua finalização. Durante a elaboração, foram realizados testes do instrumento de pesquisa com duas profissionais de Letras, duas de Psicologia e um profissional da área de Informática da Universidade Tuiuti do Paraná, além de seis alunos do curso de Psicologia da mesma universidade.

\section{Procedimentos}

O referido questionário foi encaminhado, por um link, aos contatos levantados a partir de pesquisa nos sites do Fórum Brasileiro de Economia Solidária (FBES), buscando os contatos com os fóruns regionais e municipais (totalizando 130 contatos); dos Conselhos Regionais de Psicologia; de entidades nacionais de psicologia (vinte); de cooperativas e redes de Economia Solidária; de cursos de Psicologia em âmbito nacional; da Associação Brasileira de Ensino de Psicologia; da Secretaria de Estado do Trabalho e Emprego; do Conselho Nacional de Desenvolvimento Científico e Tecnológico (Currículo Lattes: 257 contatos de psicólogos e psicólogas que trabalham com Economia Solidária); além de algumas universidades do território brasileiro e órgãos envolvidos com Economia Solidária. 
Obteve-se o retorno de 480 respondentes, sendo que, destes, somente 123 foram considerados válidos, por motivos variados: respondente não ser psicólogo(a), não ter experiência em Economia Solidária, não terminar de responder ao questionário, o sistema não gravar as respostas etc.

A coleta de dados ocorreu em três momentos. O primeiro aconteceu entre agosto e outubro de 2009, obtendo-se 52 questionários válidos, sendo 10 do sexo masculino e 42 do sexo feminino, com idades entre 22 e 60 anos. O segundo momento aconteceu entre junho de 2010 e março de 2011, obtendo-se a amostra de 65 respondentes válidos, sendo 14 do sexo masculino e 51 do sexo feminino, com idades entre 22 e 60 anos. Por fim, o terceira momento aconteceu entre março e outubro de 2011, com 6 respondentes válidos, sendo 2 do sexo masculino e 4 do sexo feminino, com idades entre 22 e 35 anos, todos profissionais atuantes, ou que já atuaram, na área de Economia Solidária no Brasil. Optou-se por repetir os momentos de coletas de dados devido ao alto grau de questionários considerados não válidos, bem como à dificuldade para se encontrar os referidos profissionais.

Finalmente, a análise dos dados baseou-se na amostra de 123 sujeitos, sendo 26 do sexo masculino e 97 do sexo feminino, obtida durante os três momentos de coleta supramencionados.

\section{Análise dos dados}

Os dados referentes às questões fechadas foram submetidos a análise estatística descritiva, que teve como objetivo a descrição das características dos(as) psicólogos(as) atuantes, ou que já atuaram, com Economia Solidária no Brasil, sendo possível a construção de quadros e gráficos que demonstraram objetivamente os dados coletados, visando a sua discussão. Os dados referentes às questões abertas foram categorizados e organizados por meio de quadros.

Conforme o objetivo da presente pesquisa, a partir da amostra de 123 psicólogos(as) atuantes, ou que já atuaram, com Economia Solidária no Brasil, foram encontrados os seguintes resultados.

O número de psicólogos(as) respondentes atuantes, ou que já atuaram, na Economia Solidária é predominantemente do sexo feminino, sendo 97 psicólogas e 26 psicólogos. Este resultado pode estar relacionado ao fato de que a Psicologia é uma profissão exercida predominantemente por mulheres, como mostra uma pesquisa realizada pelo Instituto Brasileiro de Opinião Pública e Estatística, Ibope (2004) sobre o perfil do psicólogo brasileiro, em que, em um total de 2000 entrevistados, $91 \%$ eram do sexo feminino e apenas $9 \%$, do sexo masculino. Sendo assim, nossa pesquisa corrobora os dados do Ibope.

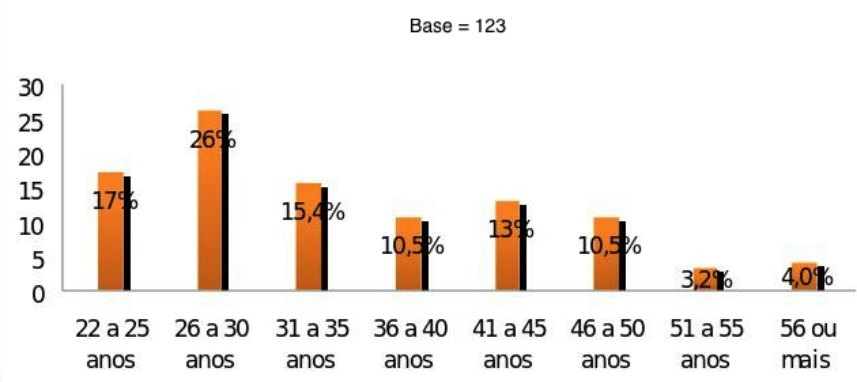

Figura 1: Perfil do psicólogo quanto a idade. Fonte: Questionário "Psicólogos(as) atuantes em Economia Solidária" 
Com relação à idade dos(as) psicólogos(as), 58,4\% da amostra tem até 35 anos, como mostra a figura 1. De acordo com a pesquisa realizada pelo Ibope (2004), a maior parte dos psicólogos brasileiros tem entre 26 e 35 anos de idade (35\%).

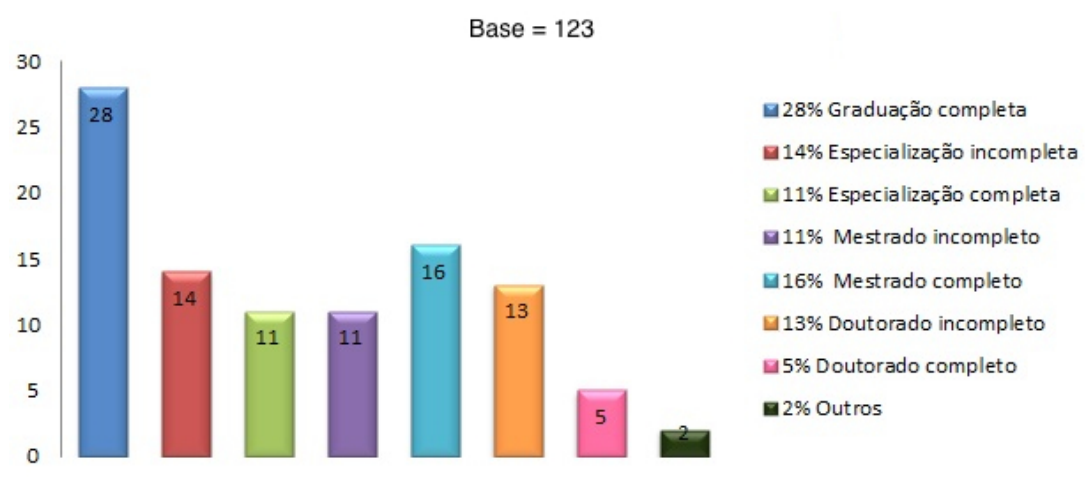

Figura 2: Perfil do psicólogo quanto a escolaridade. Fonte: Questionário "Psicólogos(as) atuantes em Economia Solidária"

Em relação ao nível de escolaridade, $28 \%$ dos respondentes possui apenas a graduação completa, seguido por $16 \%$ dos sujeitos que possuem mestrado completo e $14 \% \mathrm{com}$ especialização incompleta, conforme apresentado na figura 2. É importante observar que em Psicologia encontram-se profissionais altamente qualificados, com $26 \%$ dos respondentes com mestrado (completo e em andamento) e 18\% dos sujeitos com doutorado completo e incompleto. Ainda entre os respondentes, 19 pessoas afirmaram que possuíam outra formação em cursos de graduação, como: Administração, Assistência Social, Design de Produto, Design de Interiores, Economia, Enfermagem, Engenharia Eletrônica, Filosofia, Geografia, Matemática, Pedagogia, Turismo, Terapia Ocupacional, Letras e Direito.

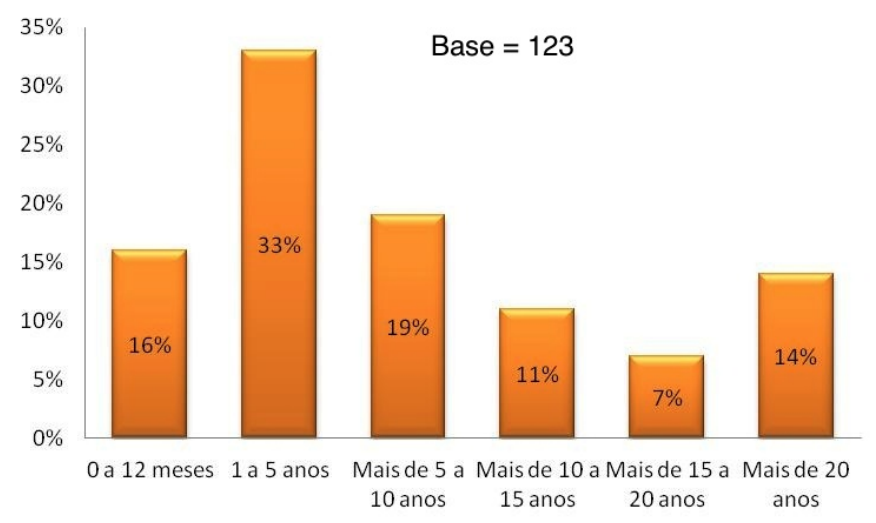

Figura 3: Perfil do psicólogo quanto ao tempo de experiência na Psicologia. Fonte: Questionário "Psicólogos(as) atuantes em Economia Solidária"

O tempo de experiência em Psicologia tem como prevalência de 1 a 5 anos entre os respondentes, como observado na figura 3. Isso pode estar relacionado ao fato de que a maioria possui idade entre 22 e 30 anos e aos cursos de graduação em Psicologia terem duração mínima de 5 anos, o que explica o pouco tempo de experiência. Também se levantou, nesta pesquisa, que, dos 123 respondentes, 108 informaram a região onde se formaram em Psicologia: Sudeste (52\%), Sul (34\%), Nordeste $(9,2 \%)$, Centro-Oeste $(3,7 \%)$ e Norte $(0,92 \%)$. Os estados mais citados foram: São Paulo (26 incidências), Paraná (16), Minas Gerais (13), Santa Catarina (12) e Espírito Santo (11). 


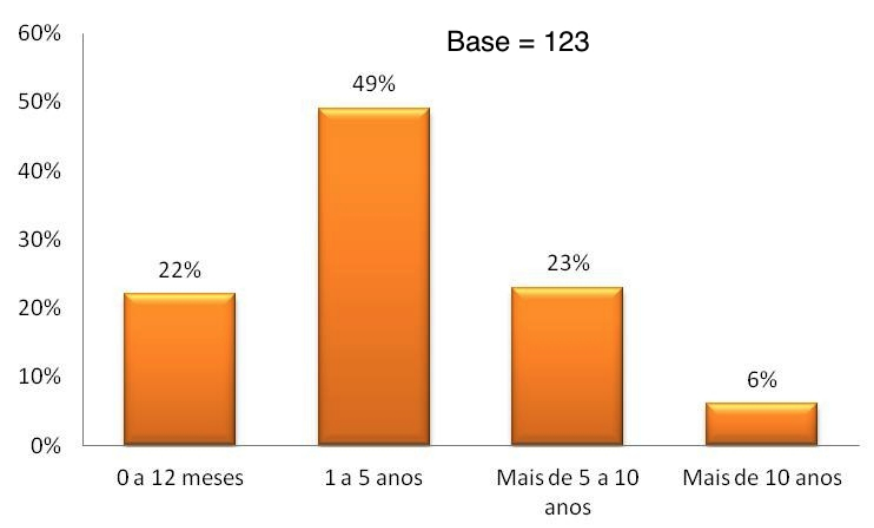

Figura 4: Perfil do psicólogo quanto ao tempo de experiência em Economia Solidária. Fonte: Questionário "Psicólogos(as) atuantes em Economia Solidária"

O tempo de experiência em Economia Solidária, como observado na figura 4, tem como prevalência de 1 a 5 anos (49\%). Esses dados podem estar relacionados ao fato de que a Economia Solidária é um movimento recente no Brasil, que revigorou no país com a crise econômica social das décadas de 1980 e 1990 (Singer, 2002), quando os primeiros empreendimentos econômicos solidários começaram a ganhar mais destaque, tornando-se mais comum a partir da metade da década de 1990, como resposta dos trabalhadores às novas formas de exclusão e exploração no mundo do trabalho (Coutinho et al., 2005).

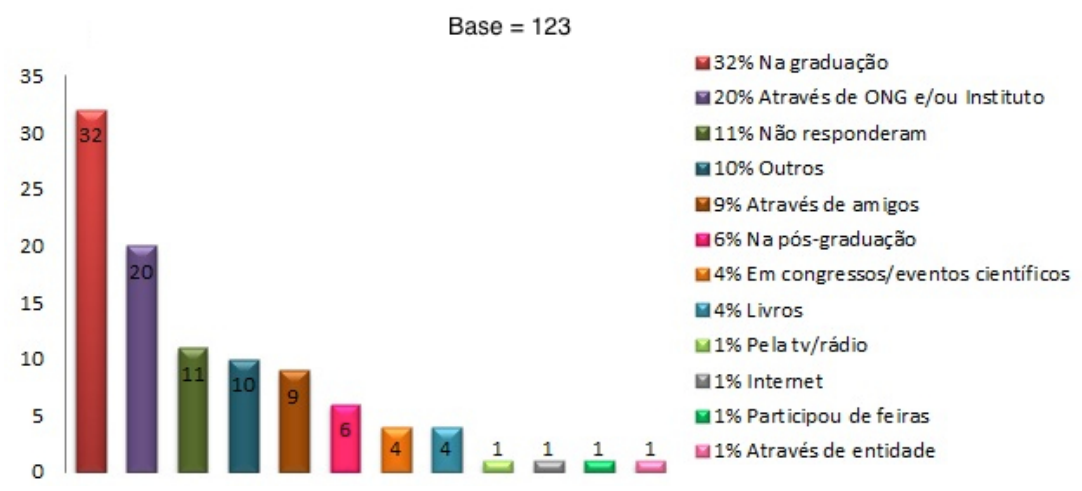

Figura 5: Perfil do psicólogo quanto a como conheceu a Economia Solidária. Fonte: Questionário "Psicólogos(as) atuantes em Economia Solidária"

Dos entrevistados, 32\% tiveram acesso à Economia Solidária como campo de atuação na graduação, por meio de conversas informais com o professor, conteúdo de disciplina, curso de extensão, estágio curricular e pesquisa (iniciação científica e trabalho de conclusão de curso). 20\% dos sujeitos conheceram a Economia Solidária por meio de ONGs e/ou institutos. Observou-se que o grande fomentador de estudos sobre Economia Solidária é a graduação. Nesse sentido, é preciso pensar sobre a viabilidade dos cursos de Psicologia inserirem em seus conteúdos este campo de atuação e de conhecimento.

Quando perguntados se consideram importante terem tido uma disciplina com conteúdos de Economia Solidária durante a graduação, 51 respondentes concordaram, contra 7 que não concordaram. No entanto, tivemos 65 pessoas que não responderam. As disciplinas mais citadas para se apropriar deste conteúdo, na opinião dos respondentes, foram: Psicologia Social (22 incidências), Psicologia do Trabalho (13), Psicologia Comunitária (3) e Sociologia, Educação e Processos Grupais (1 cada). 


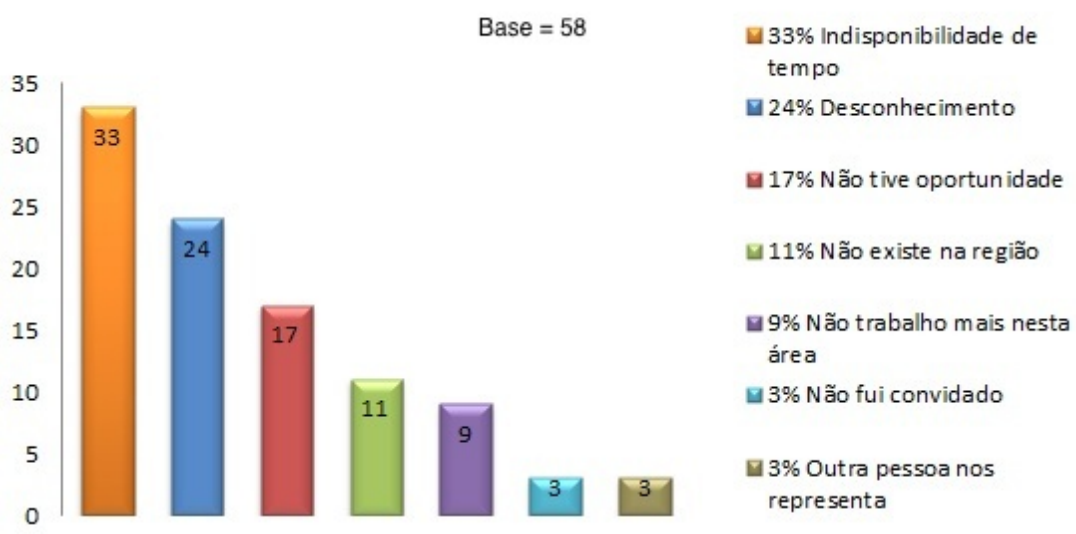

Figura 6: Perfil do psicólogo quanto a motivos para não participação nos Fóruns Regional e/ou Estadual de Economia Solidária. Fonte: Questionário "Psicólogos(as) atuantes em Economia Solidária"

A Economia Solidária é um movimento político que busca políticas públicas junto ao Estado. Promoveu, nos anos de 2006 e 2010, duas conferências nacionais em que a sociedade, por meio dos três segmentos (entidades de apoio, empreendimentos econômicos solidários e gestores públicos), foi convidada a participar de fóruns regionais e estaduais elegendo delegados para as respectivas conferências nacionais. Pela amostra apresentada, os(as) psicólogos(as) mostraram-se medianamente atuantes em fóruns, com 115 respondentes que afirmaram terem participado de um ou mais fóruns, sendo 56 participações em fóruns regionais e $59 \mathrm{em}$ estaduais, enquanto 67 não participaram de fóruns regionais e 64 dos estaduais, totalizando 131 respondentes. Entre os motivos alegados para a não participação, encontraram-se os seguintes: indisponibilidade de tempo (19 incidências), desconhecimento (14), não ter oportunidade de participar (10), não ter fórum em sua região (6), não trabalhar mais na área (5), não ser convidado (2) e já existir outra pessoa no grupo de trabalho responsável por representá-lo (2), conforme se observa na figura 6.

Esta pesquisa constatou que os(as) psicólogos(as) que participam do movimento da Economia Solidária o fazem se posicionando fortemente no segmento das Entidades de Apoio, compreendidas como entidades que fomentam e apoiam a Economia Solidária, com 59\% dos respondentes; seguido pelo segmento dos representantes do poder público (federal, estadual, municipal e Distrito Federal), como gestores, administradores públicos, Poder Legislativo e Poder Judiciário (20\%); organizações e ciências jurídicas, administrativas e organizacionais, com 12\%; e o segmento dos empreendimentos econômicos solidários e suas organizações de representação, com 9\%, conforme apresentado na figura 7 .

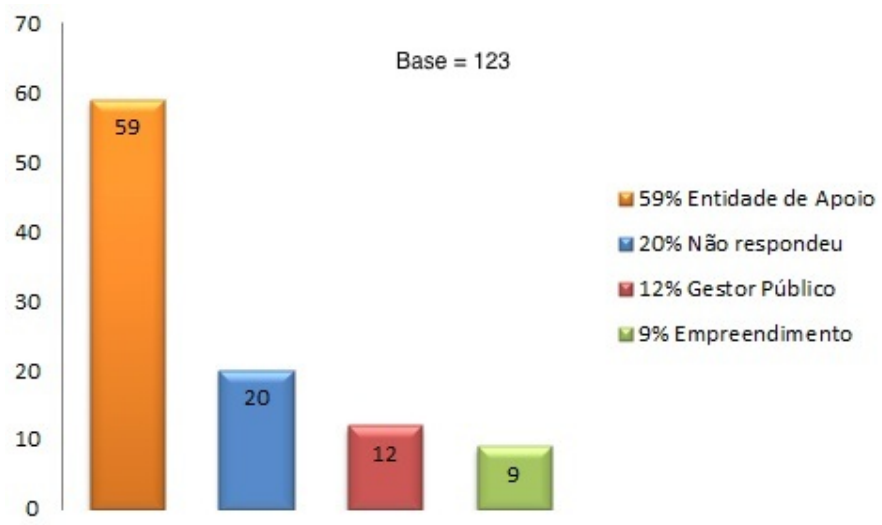

Figura 7: Perfil do psicólogo quanto ao segmento de atuação na Economia Solidária. Fonte: Questionário "Psicólogos(as) atuantes em Economia Solidária" 


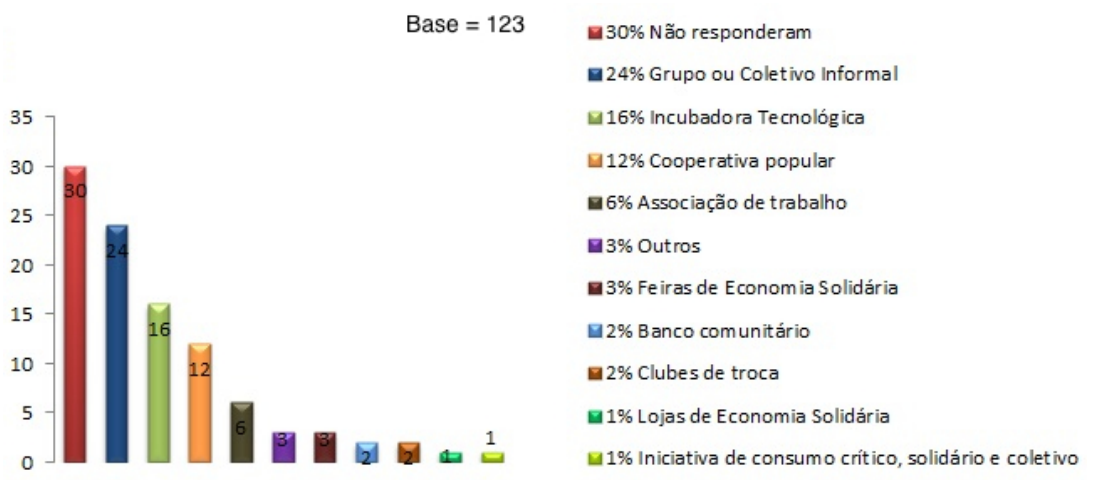

Figura 8: Perfil do psicólogo quanto ao tipo de empreendimento solidário em que atua no momento. Fonte: Questionário "Psicólogos(as) atuantes em Economia Solidária”

Já os tipos de empreendimentos solidários para os quais os(as) psicólogos(as) mais atuam, como observado na figura 8 acima, foram: grupo ou coletivo informal (24\%), incubadoras tecnológicas $(16 \%)$, cooperativas populares (12\%), associação de trabalho (6\%), feiras de Economia Solidária (3\%), banco comunitário (2\%) e os especificados pelos respondentes no quesito "outros" (3\%), tais como: entidade de fomento à Economia Solidária, pesca artesanal, assessoria de entidade de representação de empreendimento e fase de planejamento de uma incubadora.

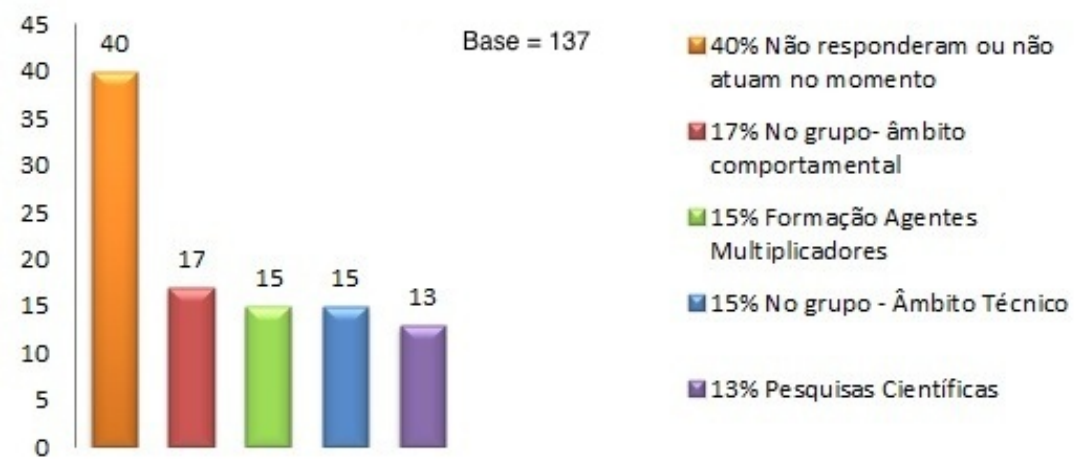

Figura 9: Perfil do psicólogo quanto à forma de atuação na Economia Solidária. Fonte: Questionário "Psicólogos(as) atuantes em Economia Solidária"

Em relação à forma de atuação do profissional, os respondentes puderam se posicionar em mais de uma resposta. Encontrou-se a seguinte distribuição: $17 \%$ alegaram atuar no grupo no âmbito comportamental. Já na formação de agentes multiplicadores e na atuação no grupo no âmbito técnico, foram 15\%. Com pesquisas científicas, foram 13\%. Além disso, 40\% dos sujeitos não responderam ou não atuavam no momento com a Economia Solidária, como se pode observar na figura 9.

A seguir, serão apresentados os temas desenvolvidos pelo profissional de Psicologia junto ao empreendimento econômico solidário. 
Quadro 1: Temas trabalhados pelo(a) psicólogo(a) com o empreendimento econômico solidário no âmbito comportamental

\begin{tabular}{|l|c|}
\hline \multicolumn{1}{|c|}{ Temas } & Incidência \\
\hline Relacionamento interpessoal & 16 \\
\hline Gestão cooperativa - autogestão & 15 \\
\hline Formação dos cooperados: individual versus coletivo & 14 \\
\hline Processo de tomada de decisão & 14 \\
\hline Administração de conflitos & 13 \\
\hline Acompanhamento do grupo - ouvir e orientar os participantes do empreendimento econômico solidário & 13 \\
\hline Formação dos cooperados: competitividade versus cooperação & 12 \\
\hline Formação dos cooperados: construção de autonomia & 12 \\
\hline Aprender a conviver com as diferenças & 12 \\
\hline Integração e união do grupo & 11 \\
\hline Comunicação humana & 10 \\
\hline Programa de saúde ocupacional & 3 \\
\hline Manejo do estresse & 2 \\
\hline
\end{tabular}

Nota: Dados levantados do questionário "Psicólogos(as) atuantes em Economia Solidária"

Quadro 2: Temas trabalhados pelo(a) psicólogo(a) com o empreendimento econômico solidário no âmbito técnico

\begin{tabular}{|c|c|}
\hline Temas & Incidência \\
\hline Gestão Básica - métodos e processos de produção em Economia Solidária & 12 \\
\hline Inserção do produto no mercado & 10 \\
\hline Desenvolvimento local & 10 \\
\hline Relações de trabalho assalariado - consciência crítica sobre o mundo do trabalho & 9 \\
\hline Comércio justo e solidário & 6 \\
\hline A importância da rede de matéria-prima, produção, comércio, consumo e sustentabilidade & 6 \\
\hline Plano de negócio - gestão básica & 5 \\
\hline Organização de redes - integração entre campo e cidade & 5 \\
\hline Inclusão social & 5 \\
\hline Políticas públicas em Economia Solidária & 5 \\
\hline Técnicas de separação e classificação de materiais recicláveis & 4 \\
\hline Consumo consciente e solidário & 4 \\
\hline Montagem do regimento do grupo cooperado & 4 \\
\hline Uso da moeda solidária/comunitária & 3 \\
\hline Marketing - divulgação e formação de preço & 3 \\
\hline Planejamento estratégico & 3 \\
\hline Transferência de tecnologia - informática & 2 \\
\hline Microcrédito e finanças solidárias & 2 \\
\hline Economia Solidária e EJA - educação emancipadora & 2 \\
\hline Marco legal & 2 \\
\hline Como abrir um empreendimento? & 2 \\
\hline Mulher e a Economia Solidária & 1 \\
\hline Contabilidade básica & 1 \\
\hline Padaria comunitária & 0 \\
\hline
\end{tabular}

Nota: Dados levantados do questionário "Psicólogos(as) atuantes em Economia Solidária" 


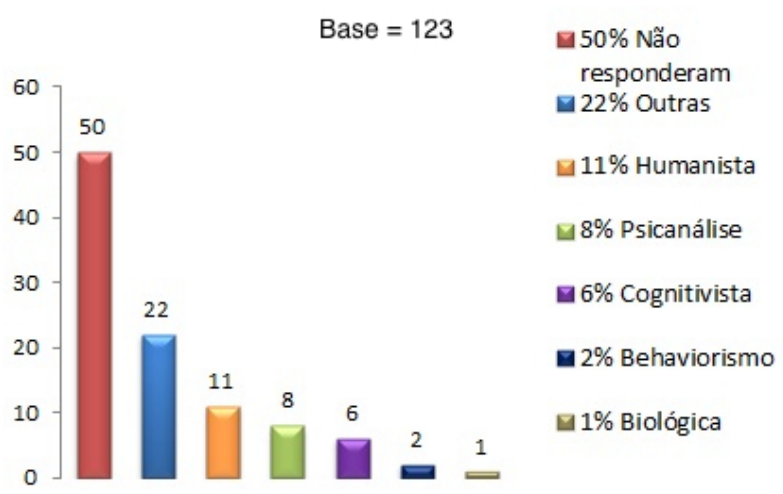

Figura 10: Perfil do psicólogo quanto à linha teórica adotada para trabalhar com economia solidária. Fonte: Questionário "Psicólogos(as) atuantes em Economia Solidária"

Sobre a linha teórica utilizada, observada na figura 10, 22\% dos(as) psicólogos(as) responderam o quesito "outras", em que a maior incidência foi a teoria sócio-histórica, com 6 incidências, seguido de psicologia social (5), análise institucional (4), psicologia social crítica (3), psicossociologia e psicodrama (ambas com 2), fenomenologia existencial, sistêmica e psicologia comunitária (1 cada).

Chama a atenção o alto número dos que não responderam (50\%), levantando-se a hipótese de o(a) psicólogo(a) não ter clareza de que tipo de abordagem teórica utiliza em seu cotidiano e/ou não estar sendo devidamente preparado pela graduação e/ou a graduação não perceber este novo campo de atuação, já que um alto índice de respondentes (55) disseram não ter tido o conteúdo de Economia Solidária oferecido por nenhuma disciplina do curso, em oposição a apenas 14 pessoas que disseram ter visto este conteúdo em disciplinas como: Psicologia Comunitária (4 incidências), Psicologia do Trabalho e Psicologia Social (ambas com 3), Psicologia Social do Trabalho, Relações Sociais do Trabalho, Psicologia Institucional e Psicologia e Movimentos Sociais (1 cada).

Conforme mencionado anteriormente, os respondentes se posicionaram de maneira favorável à inclusão de uma disciplina com conteúdos de Economia Solidária na graduação, sendo as disciplinas de Psicologia Social e do Trabalho as citadas como mais adequadas.

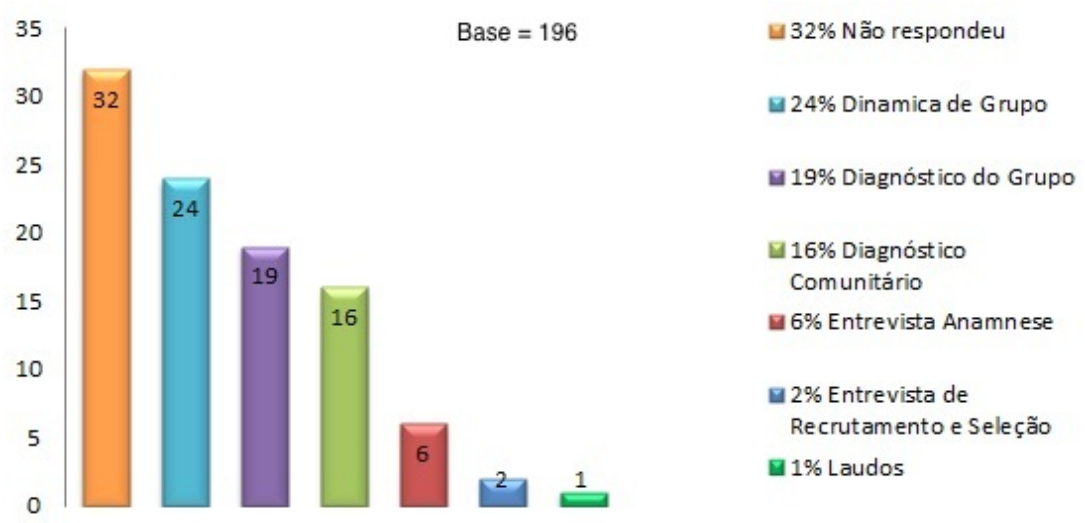

Figura 11: Perfil do psicólogo quanto às técnicas utilizadas com a Economia Solidária. Fonte: Questionário "Psicólogos(as) atuantes em Economia Solidária"

A base da figura 11 difere das demais, pois os(as) psicólogos(as) atuantes na Economia Solidária utilizam-se de várias técnicas em sua atuação. São estas predominantemente: dinâmica de grupo (24\%), diagnóstico do grupo (19\%) e diagnóstico comunitário (16\%). 
A partir das questões abertas em que se solicitava ao respondente que relatasse brevemente sua atual e/ou última experiência com Economia Solidária, levantaram-se as seguintes experiências, separadas por temas, respectivamente, nos quadros 3, 4, 5 e 6 .

O item mais comentado foi o desenvolvimento da autogestão, sendo primordial para a gestão de um empreendimento econômico solidário (quadro 3). Além disso, grande parte dos(as) psicólogos(as) atua com resolução de conflitos interpessoais e/ou intergrupais. Uma demanda premente é a contradição entre viver em um sistema capitalista e trabalhar em uma organização solidária. Os valores são opostos, e as pessoas ainda não estão plenamente preparadas para viver sob os princípios da Economia Solidária, sendo isso uma grande fonte de conflitos. As relações interpessoais e grupais são outros pontos fortemente trabalhados pelos(as) psicólogos(as), pois se tem um sistema que promove o trabalho coletivo e as decisões coletivas, e a convivência neste novo foco exige maior atenção da psicologia. Ainda no quadro 3, percebe-se que há mais demanda pelo tipo de relacionamento voltado para o nível grupal do que propriamente por questões que envolvam a formação política desses trabalhadores.

Quadro 3: Atividades desenvolvidas por psicólogos em relação ao acompanhamento e intervenção psicossocial do grupo de trabalho

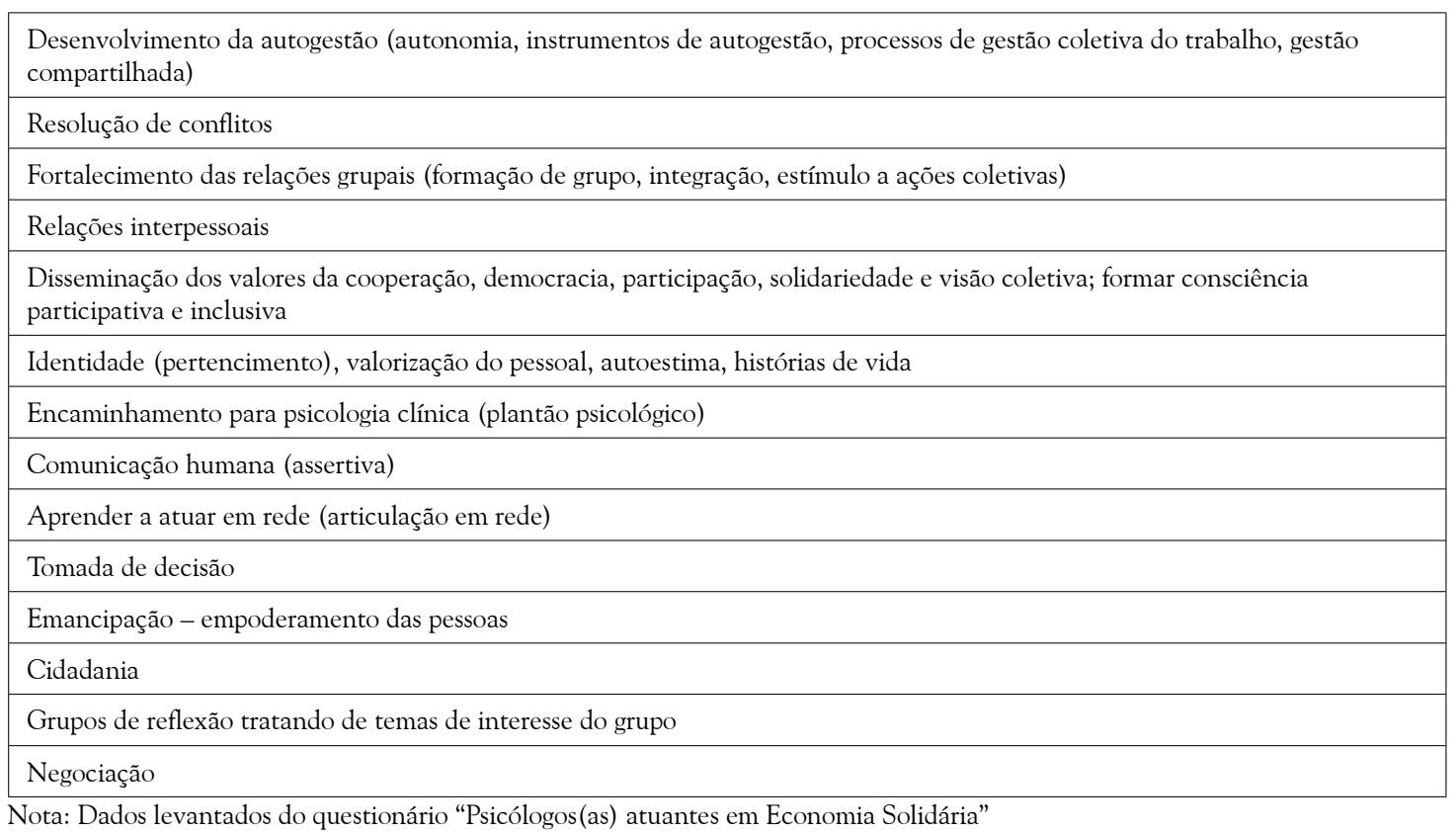

Já no quadro 4, são relatadas as atividades desenvolvidas pelos(as) psicólogos(as) em relação à intervenção técnica do grupo de trabalho, ou seja, todas as intervenções que contemplem ações para o bom desenvolvimento do empreendimento econômico solidário em termos do processo produtivo. Nesse sentido, os(as) psicólogos(as) podem atuar tanto na preparação das pessoas para desenvolverem a formalização de uma cooperativa ou associação de trabalho quanto na melhoria dos processos internos de produção, bem como de comercialização. É um trabalho fortemente desenvolvido por equipes multidisciplinares, principalmente em incubadoras tecnológicas de cooperativas populares e/ou entidades de apoios. Outro item forte desse processo perpassa por formação e capacitação, por meio de palestras, oficinas e cursos, com temas focados em refletir sobre a Economia Solidária, além daqueles que visam preparar os(as) trabalhadores(as) com formação técnica, objetivando a melhoria do produto final e a sustentabilidade de seu negócio em um mercado que não contempla os valores da Economia Solidária. Percebe-se que boa parte dos(as) trabalhadores(as), antes acostumados(as) a ter alguém "superior" para fazer a gestão da empresa, agora passa a ter de pensar, compreender e atuar de forma ampla e sistêmica em seu 
empreendimento econômico solidário, desde a aquisição da matéria-prima até a comercialização de seu produto.

Quadro 4: Atividades desenvolvidas por psicólogos(as) em relação ao acompanhamento e intervenção técnica do grupo de trabalho

\begin{tabular}{|l|}
\hline Formação de cooperativas/associaçães (formulação de estatuto social, orientação para formalização) \\
\hline Condução de reuniões \\
\hline Elaboração de atas e/ou relatórios \\
\hline Encaminhamento de documentos à Junta Comercial \\
\hline Registro de marcas junto ao INPI \\
\hline Planejamento de empreendimentos e planejamento estratégico participativo \\
\hline $\begin{array}{l}\text { Organização do empreendimento (organização de documentação organizacional, do trabalho, da produção, da comercialização } \\
\text { e de processos administrativos) }\end{array}$ \\
\hline Gestão (controle financeiro, divisão lucros) \\
\hline Aplicação de questionários diagnósticos \\
\hline $\begin{array}{l}\text { Formação e capacitação: palestras, cursos, oficinas, seminários (elaboração de materiais didáticos e cartilhas; desenvolvimento } \\
\text { de metodologia de formação; alfabetização de trabalhadores - junto com pedagogo - qualificação para trabalhar com questões } \\
\text { técnicas, tais como: cerâmica, reciclagem, inclusão digital e captação de recursos; formação em Economia Solidária, formação } \\
\text { de preço e atendimento ao cliente) }\end{array}$ \\
\hline Plano de negócios \\
\hline Mediação e animação de trocas (clubes de troca) \\
\hline
\end{tabular}

Nota: Dados levantados do questionário "Psicólogos(as) atuantes em Economia Solidária"

Os profissionais de psicologia encontram no espaço das entidades de apoio (incubadoras, universidades e ONGs, por exemplo) forte entrada para desenvolver seu trabalho, conforme demonstra o quadro 5. Tais entidades de apoio aproximam não só os(as) psicólogos(as), mas também uma equipe multidisciplinar, dos grupos de trabalhadores que atuam sob os princípios da Economia Solidária. A questão que se coloca é se o profissional está sendo preparado na graduação para atuar com esta forma de organização social do trabalho. Quando perguntados se tiveram alguma disciplina relativa a Economia Solidária na faculdade, grande parte disse que não e que acha importante sua inclusão na grade curricular.

Quadro 5: Atividades desenvolvidas por psicólogos(as) atuantes em entidades de apoio (assessorias)

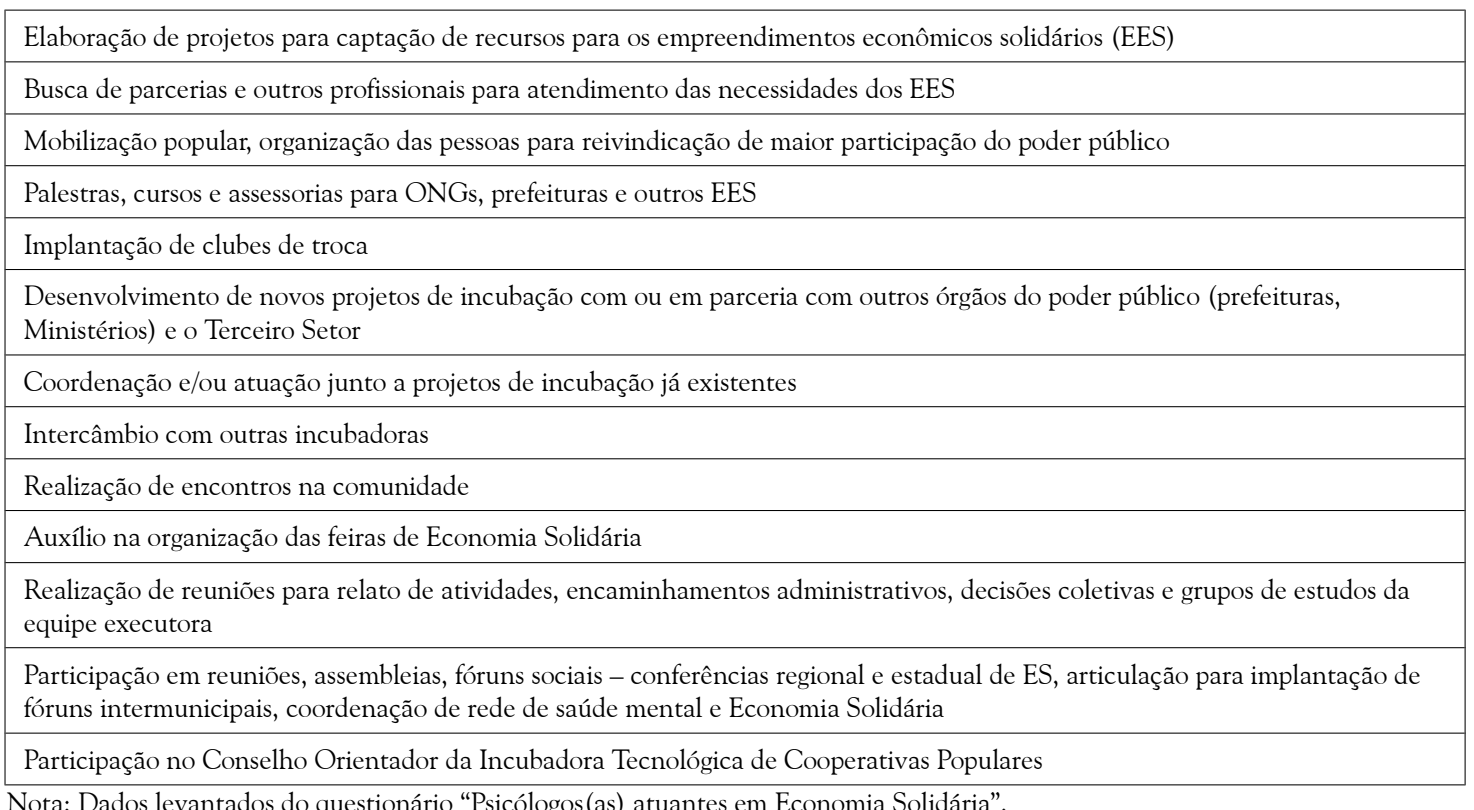


Há também uma forte entrada do(a) psicólogo(a) em atividades de pesquisa e aprofundamento do tema, conforme demonstrado no quadro 6. Além de promoverem o aumento do conhecimento para outras esferas da vida social, os formatos metodológicos das pesquisas são de forma processual e de campo, refletindo sobre o movimento da Economia Solidária e suas interfaces, agregando, com isso, maior maturidade profissional para o campo de atuação.

Quadro 6: Atividades desenvolvidas por psicólogos(as) em pesquisas em Economia Solidária

\begin{tabular}{|l|}
\hline $\begin{array}{l}\text { Desenvolvimento de pesquisas de mestrado e doutorado (compreensão de aspectos subjetivos envolvidos no processo de } \\
\text { formação de grupos de ES; compreensão da ação coletiva dos grupos; práticas de consumo; impacto da participação de pessoas } \\
\text { em cooperativas populares de trabalho em outras esferas de sua vida social; pesquisa em empresas autorrecuperadas; banco } \\
\text { comunitário; entre outros) }\end{array}$ \\
\hline Participação em eventos científicos com apresentação de pôster, comunicação oral e publicação de artigos em anais de eventos \\
\hline Elaboração de artigos científicos \\
\hline Desenvolvimento de grupos de estudos \\
\hline Discussão metodológica sobre intervenções em Economia Solidária \\
\hline
\end{tabular}

Observou-se que os quadros 3, 4, 5 e 6 acabam corroborando as atividades previamente colocadas nos quadros 1 e 2 .

\section{Considerações Finais}

Para alguns, a Economia Solidária não passa de uma proposta para combater as consequências advindas do modelo econômico capitalista, incluindo os(as) trabalhadores(as) no mundo do trabalho. Para outros, é considerada um modelo econômico para superar o capitalismo. Seja a Economia Solidária entendida como coadjuvante do sistema ou como um modelo econômico, é importante compreender a atuação do(a) psicólogo(a) neste contexto social.

O movimento da Economia Solidária é uma oportunidade de resgate da dignidade humana e desenvolvimento de autoajuda e ajuda mútua, o que é essencial à saúde de todos os indivíduos, do ponto de vista da psicologia. Dessa forma, a atuação deste profissional torna-se de suma importância para trabalhar na prevenção e na promoção de saúde do trabalhador, na capacitação e na conscientização dos membros do sistema cooperativo e na intervenção em questões importantes que surgem no cotidiano, decorrentes da mudança a um sistema oposto ao capitalista.

Os resultados desta pesquisa mostraram evidências de que a atuação do(a) psicólogo(a) na Economia Solidária está pautada no contato direto com os(as) trabalhadores(as) tendo em vista: a orientação no desenvolvimento da autogestão, a resolução de conflitos, o fortalecimento das relações grupais e também o assessoramento no diagnóstico e na gestão dos empreendimentos cooperativos. Além disso, mostraram-se fortemente empenhados em projetos de pesquisas e produção de conhecimento sobre a área da Economia Solidária no que tange à compreensão dos aspectos subjetivos envolvidos no processo de formação de grupos de Economia Solidária; às práticas de consumo; ao impacto da participação de pessoas em cooperativas populares de trabalho em outras esferas de sua vida social; à pesquisa em empresas autorrecuperadas; aos bancos comunitários; entre outros.

As áreas da Psicologia citadas como as mais adequadas para se trabalhar com esta demanda foram a Psicologia Social e a Psicologia do Trabalho. 
Já com relação à área da Psicologia Organizacional e do Trabalho, urge que ela se volte realmente para o trabalho e o trabalhador. Pois, ao ver o trabalho e o trabalhador sob o modo de produção capitalista, atuar-se-á visando a lógica do capital: o lucro, em detrimento do ser humano e da valorização do trabalho. Nesse sentido, serão privilegiados a exclusão, o individualismo, a competição, a heterogestão (hierarquia), a concentração de renda, a concentração do saber e, consequentemente, do poder, formando separações entre classes e acentuando as diferenças sociais. Por outro lado, ao ver o trabalho e o trabalhador sob o foco dos princípios da Economia Solidária, se atuará na integração das pessoas, no coletivo, na cooperação, na solidariedade, na autogestão, na distribuição de renda, de saberes e de poder, visando uma relação social voltada para uma forma diferenciada de pensar a economia e o mundo, no sentido de repensar os modos de produção, de comercialização e de consumo. Será buscada, também, a melhoria das relações entre as pessoas e a natureza, além de mobilizar as comunidades na busca de melhores condições de bem viver (Franco, 1988).

Percebeu-se que a atuação do(a) psicólogo(a) no movimento da Economia Solidária vai muito além da resolução de conflitos em grupos, e isto é visível no relato de suas experiências. $\mathrm{Na}$ realidade, convive-se com situações muito contraditórias. Por isso, a mudança de valores e de atitudes se faz necessária, pois a ideia de que não há alternativas ao capitalismo conseguiu um nível de aceitação que provavelmente não tem precedentes na história do capitalismo mundial. No entanto, nos últimos anos, essa situação começou a mudar, a partir do renascimento do ativismo em favor de uma globalização contra-hegemônica. E, apesar do passado recente do movimento da Economia Solidária para construir uma identidade e do resgate de um projeto histórico, é necessária maior aproximação da psicologia com os atores sociais desse movimento, para o estabelecimento de estratégias de resgate da cidadania e da consciência coletiva, estimulando a reflexão dos(as) trabalhadores(as) sobre seu potencial como agentes de mudança e autores de suas próprias histórias.

\section{Referências}

Arroyo, J. C. T. (2008). Cooperação econômica versus competitividade social. Revista Katálysis, 11 (1), 73-83.

Brito, R. C. \& Figueiredo, A. L. (1997). Desenvolvimento comunitário: uma experiência de parceria. Psicologia Reflexão e Crítica, 10 (1), 181-191.

Cartes, O. (2006). História do Trabalho. Texto disponível na Internet: www.guatimozin.org.br/artigos/ hist_trabalho.htm. [3 abril 2011].

Cartilha da Campanha Nacional de Mobilização Social. Economia Solidária, Outra Economia Acontece (2007). Brasília: TEM, SENAES, FBES.

Coser, D. S. \& Cortegoso, A. L. (2007). Economia Capitalista x Economia Solidária: práticas de recrutamento e seleção de pessoal. Artigo disponível na Internet: www.poli.usp.br/p/augusto.neiva/nesol/Publicacoes/ [5 outubro 2009].

Coutinho, M. C., Beiras, A., Picinin, D. \& Lükmann, G, L. (2005). Novos Caminhos, cooperação e solidariedade: a Psicologia em empreendimentos solidários. Psicologia $\mathbb{E}$ Sociedade, 17 (1), 17-28.

Franco, V. C. (1988). A Natureza das técnicas de intervenção em comunidades. Psicologia $\mathscr{E}$ Sociedade, 3 (5), 70-73.

Freitas, M. F. Q. (1999). Psicologia na comunidade, psicologia da comunidade e psicologia (social) comunitária: práticas da psicologia em comunidades nas décadas de 60 a 90, no Brasil. In R. H. F Campos (Org.), Psicologia social comunitária: da solidariedade à autonomia. Petrópolis: Vozes.

IBOPE (2004). Pesquisa de opinião com psicólogos inscritos no Conselho Federal de Psicologia. Artigo disponível na Internet: www.pol.org.br/pol/export/sites/default/pol/publicacoes/publicacoesDocumentos/Pesquisa_ IBOPE.pdf [10 agosto 2011]

Lima, J. C. (2008). Reestruturação industrial, desemprego e autogestão: as cooperativas do Vale do Sinos. Sociologias, 19, 212-249. 
Rosenfield, C. L. (2003). A autogestão e a nova questão social, repensando a relação do individuo com a sociedade. Civitas, 3 (2), 395-415.

Singer, P. (2002). Introdução à Economia Solidária. São Paulo: Perseu Abramo.

Souza, A. I. (2006). Entrevista concedida à autora em 28/03/06.

Spink, P. K. (2004). Redes solidárias, autogestão e solidariedade. In N. M. F. Guareschi. (Org.), Estratégias de invenção do presente: a psicologia social no contemporâneo. Porto Alegre: PUC-RS.

Veronese, M. V. \& Guareschi, P. (2005). Possibilidades solidárias e emancipatórias do trabalho: campo fértil para a prática da psicologia social crítica. Psicologia $\mathcal{E}$ Sociedade, 17 (2), 58-69.

Zanelli, J. C. \& Bastos, A. V. B. (2004). Inserção do profissional psicólogo em organizações e no trabalho. In J. C. Zanelli, J. E. Borges-Andrade \& A. V. B. Bastos (Orgs.), Psicologia, organizações e trabalho no Brasil. Porto Alegre: Artmed.

Endereços para Correspondência

iararaittz@hotmail.com,marilene.zazula@hotmail.com

Recebido em: 10/05/2012

Revisado em: 22/10/2012

Aprovado em: 25/10/2012 